\title{
SEDUCTORA I SEDUÏDA: ALGUNES DADES SOBRE LES RELACIONS DE LA NARRATIVA DE CARME RIERA AMB ITÀLIA
}

\author{
LUISA COTONER CERDÓ \\ Universitat de Vic
}

\begin{abstract}
Aquest article vol analitzar algunes dades de l'obra de Carme Riera que fan palesa la predilecció que l'escriptora mallorquina manifesta cap a la cultura, les terres i les gents d'Itàlia, fins al punt que, tot repassant els escenaris, els personatges, les referències i els jocs intertextuals que apareixen a diverses obres rierianes, podem afirmar que n'està seduïda. D’altra part, si examinem la recepció de la seva narrativa en aquest país, fonamentalment, la traducció a l'italià de tres novel-les i les reaccions crítiques que han suscitat en medis acadèmics i de comunicació, podem concloure que Riera ha seduït, si més no selectivament, bona part del públic d'aquelles terres. Aquí es poden trobar un bon grapat de testimonis.

PARAULES CLAU: Carme Riera, Itàlia, recepció literària, traducció, art, literatura.

Seductora y seducida: algunos datos sobre las relaciones entre la narrativa de Carme Riera e Italia

Este artículo pretende analizar ciertos detalles de la obra de Carme Riera que ponen de manifiesto la predilección que la escritora mallorquina siente por la cultura, las tierras y las gentes de Italia, hasta el punto de que basta con repasar los escenarios, personajes, referencias y juegos intertextuales que aparecen en algunas de sus obras para poder afirmar que ha sido seducida por aquel bellísimo país. Por otra parte, si examinamos la recepción que su obra narrativa ha tenido allí, llegaremos a la conclusión de que Riera ha seducido también a buena parte del público italiano, como demuestran los numerosos testimonios recogidos.
\end{abstract}

PALABRAS CLAVE: Carme Riera, Italia, recepción literaria, traducción, arte, literatura.

Seducer and Seduced: some aspects of the relationship between Carme Riera's narrative and Italy

This article aims to analyze features in the work of Carme Riera that disclose the predilection that the Majorcan writer shows towards the culture, the land and the people of Italy, to the point that reviewing the settings, characters, references and intertextual games that appear in several of her works, we can say that she has been seduced. Furthermore, if we examine the reception of her narrative in that country, namely, the Italian translation of three novels and the critical reactions that have arisen in both academia and the media, we can conclude that Riera

Cotoner Cerdó, Luisa (2013), "Seductora i seduïda: algunes dades sobre les relacions de la narrativa de Carme Riera amb Itàlia”, Lectora, 19: 49-63. ISSN: 1136-5781 D.O.I.: XXXXXXXXX. Recepció: 1 de juny 2012 - Acceptació: 30 de desembre 2012 
has also seduced, at least selectively, most of the readers in those lands, as evidenced by the numerous testimonials included here.

KEY WORDS: Carme Riera, Italy, literary reception, translation, art, literature.

Sono innamorata senza mezzi termini dell'Italia [e di Roma] e ci vengo appena posso, amo e conosco la letteratura italiana contemporanea. Oltre ai classici Pavese, Pratolini, Vittorini, Bassani, Calvino, Eco, Consolo, conozco personalmente e ammiro Francesca Duranti e Melania Mazzuco...

Amb aquestes paraules Carme Riera es mostrava seduïda per Itàlia, tot declarant el seu amor per la terra, la cultura i la literatura italiana, a la periodista Valentina Pigmei del diari La Stampa, amb motiu de la traducció a l'italià d'una de les seves novel.les (Pigmei, 2003). Aquest article vol, en primer lloc, fer palesa aquesta predilecció, ni que sigui oferint només algunes dades de la presència d'Itàlia en escenaris, personatges i referents culturals que podem trobar des del principi de la seva carrera literària, ${ }^{1}$ i de manera especial en les novel.les Una primavera per a Domenico Guarini (1981), Dins el darrer blau (1994), Cap al cel obert (2000) i Natura quasi morta (2011). A més a més, volem passar revista a la recepció que l'obra de Riera ha tingut a Itàlia. És ben sabut que tota escriptura intenta d'alguna manera seduir l'Altre. M'atreveixo fins i tot a dir que la seducció del públic lector és el principal objectiu de la literatura, atès que si el missatge no arriba o no té resposta és com aquell enamorat, víctima d'un miratge, que comprova afligit que el seu amor és engolit per la indiferència. Si com ha afirmat espesses vegades a entrevistes diverses Riera escriu per seduir, ${ }^{2}$ no podíem tampoc deixar de comprovar quin grau de seducció ha assolit la narrativa rieriana entre el públic italià i si en aquest cas es produeix també una relació de complicitat amb els lectors, que és una de les característiques més destacades del seu estil literari. En aquest sentit, calia doncs establir, ni que fos a grans trets, la recepció a Itàlia de les obres de l'autora mallorquina a través de les traduccions a la llengua de Petrarca de tres de les seves novel-les i de la resposta que en varen suscitar a la premsa italiana. Començarem per l'anàlisi d'aquest vessant.

\section{La recepció a Itàlia de l'obra de Riera: petita crònica d'una seducció selectiva}

Tot i que, com veurem més endavant, la novel-la més 'italiana' de Riera és Una primavera per a Domenico Guarini (1981), la seva primera obra traduïda a l'italià

\footnotetext{
${ }^{1}$ Val a dir que Riera no és una excepció, atès que és mallorquina i, com és sabut, les relacions polítiques, mercantils i culturals de Mallorca amb les terres italianes es remunten a l'Edat Mitjana, s'intensificaren entre els segles xv i xvii, i es perllonguen durant el segle XVIII.

${ }^{2}$ Vegeu Carme Riera (1989), potser la primera vegada que va fer aquesta afirmació per escrit.
} 
va ser Dins el darrer blau (1994), ${ }^{3}$ transformada en Dove finisce il blu (1997) per mà de Francesco Ardolino. El text recrea el món de la Mallorca de finals del segle XVII, on s'entrecreuen cortesans, comerciants, frares, inquisidors, pagesos i artesans, meuques i bandolers, i "la gent del carrer", és a dir, els criptojueus i conversos, que protagonitzaren els fets històrics que succeïren a Ciutat entre el 1688 i el 1691. El relat de l'intent de fugida cap a la llibertat i el final tràgic del grup encapçalat per Gabriel Valls de Valls Major a les fogueres de la Inquisició, impressionà Ardolino fins al punt de convèncer l'editor Elido Fazi perquè s'embarqués en l'aventura de publicar-lo a Itàlia. I la va encertar: aquesta història novel-lada, on la ciutat de Livorno (Liorna) juga un paper transcendental a la trama, va rebre l'any 2000 el prestigiós Premi Vittorini de Siracusa, atorgat a la millor obra estrangera traduïda a l'italià. ${ }^{4}$ Tanmateix, abans d'aquesta distinció, la premsa italiana s'havia fet ressò del llibre a través de recensions i ressenyes a diversos diaris i revistes, ${ }^{5}$ entre les quals destaco l'article de Nancy [àlias d'Alfonsina] De Benedetto a Ex libris (núm. 7, abril de 1998) on, a banda d'elogiar "la bella traduzione", fa una síntesi de l'evolució de les formes literàries de Riera, des del gènere epistolar i melancòlic, iniciat el 1975 amb Te deix, amor, la mar com a penyora, fins arribar al domini de les diverses tècniques narratives per emmarcar episodis perfectament documentats històricament amb altres successos i personatges inventats - hores d'ara és un dels trets característics que Riera domina de manera magistral. L'article es conclou tot esmentant la nota final de Dins el darrer blau, on l'autora declara que demanar perdó, per aquells fets i per les seves tràgiques conseqüències, "és una de les intencions de la novel.la".

Fruit de l'èxit del premi van ser també les relacions personals que Riera va tenir l'oportunitat d'establir amb el món literari italià: l'amistat amb escriptores, com les abans esmentades Francesca Duranti i Melania Mazucco; i el respecte de crítics i catedràtics, com ara els professors Natale Tedesco i Loredana Faraci. Concretament, el Dr. Tedesco, president del Jurat del premi Vittorini, va tenir la gentilesa de desplaçar-se a Barcelona el novembre de 2000 per participar en la "Trobada internacional d'especialistes en l'obra narrativa de Carme Riera, 25 anys després de la publicació de Te deix, amor, la mar com a penyora" (Barcelona 7 i 8 de novembre de 2000), en una taula de debat sobre la "Traducció i recepció de les obres de Carme Riera a altres llengües i cultures”. Allà, entre d'altres comentaris, va qualificar la novel-la de "capolavoro" i va declarar que autors com ara Vittorini o Riera "portano un grande aiuto alla comprensione dell'identità

\footnotetext{
${ }^{3}$ Premio Nacional de Narrativa (1995)

${ }^{4}$ Els reptes que el traductor va haver d'assolir, els explica el mateix F. Ardolino (2001: 25-28).

${ }^{5}$ Vegeu Vanna Gazzola Stacchini (1998), Angela Bianchini (2003), Carlo Carlino (s/d), Nancy De Benedetto (1998: 22-23), Guillermo Carrascón (1998: 12), Riccardo Calimani (1998), Monica Bungaro (1998), Chiara Cristini (1998) i, Loredana Faraci i Natale Tedesco (2002).
} 
delle nostre regioni, alla definizione dell'originalità del loro contributo allo sviluppo della cultura europea e mediterranea."

Potser com a conseqüència del premi i de la ressonància subsegüent, quan va sortir al carrer Cap al cel obert (2000), la mateixa editorial Fazi va encarregar-ne la traducció a Francesco Ardolino. Sota el títol Verso il cielo aperto, la novellla de Riera va aparèixer a les llibreries italianes el setembre de 2002. Els editors se'n cuidaren, de fer-ne una bona propaganda, destacant a la sobrecoberta las paraules de Pere Gimferrer, qui qualificava l'obra d'“assolutamente magistrale", d'ésser "un romanzo straordinario", vinculat amb Dove finisce il blu, "primo atto del ciclo dedicato agli ebrei convertiti maiorchini di cui Verso il cielo aperto è l'ideale prosieguo".

Tot i que aquesta vegada la bellíssima traducció d'Ardolino no hi va guanyar cap premi, ${ }^{6}$ el llibre igualment va ser objecte d'atenció per part de la crítica. Riera va fer diverses entrevistes a la ràdio i a la televisió - la de Luca Marengo "Hasta siempre, Carme Riera" a la TV RadioCorriere (25/02/2003) n'és un exemple. I a la premsa van sovintejar les recensions afalagadores - he pogut constatar-ne gairebé una vintena-, ${ }^{7}$ entre les quals destaco les de Riccardo Trani (Avanti, 16/02/2003), qui proclama "Carme Riera, la nuova regina del romanzo storico"; Antonella Parisi (Gazzeta di Parma, 22/06/2003), qui li dedica una extensa crònica a la qual afirma que Riera "ha ridato vita" al gènere vuitcentista del fulletó; o Giovanna La Vecchia (Italia Sera, 18/02/2003), per a qui "Verso il cielo aperto (Fazi Editore, 348 pagine, euro 16,50), l'ultimo romanzo storico e d'amore, conferma Carme Riera come la maggiore scrittrice catalana vivente."

Sigui com vulgui, aquesta bona acollida de la novel.la cubana va preparar el terreny pel trasllat de La meitat de l'ànima (2004), girada a l'italià per Ursula Bedogni ${ }^{8}$ i igualment publicada per Fazi Editore el 2007.

També aquesta vegada la premsa va parar atenció en La metà dell'anima, tot reconeixent els mèrits de l'escriptora mallorquina. Entre d'altres, Francesca

\footnotetext{
${ }^{6}$ Segons ha pogut comprovar Francesco Ardolino, al Diccionari de la Literatura Catalana d'Àlex Broch, a l'entrada de Cap al cel obert es diu que el llibre va guanyar el Premi Vittorini, una informació que ha sortit equivocada malgrat que el traductor hagués assenyalat la incorrecció.

${ }^{7}$ Vegeu Angela Bianchini (2003), Diego Zandel (2003), Alessandra Masu (2003), Diana Ferrero (2003), Pasquale Bottone (2003), Brunella Schisa (2003), Francesco Fantasia (2003), Paolo Izzo (2003), Luisella Colombo (2003), Luigi La Rosa (2003), Valentina Pigmei (2003) i Cristina Taglietti (2002).

${ }^{8}$ Ursula Bedogni és llicenciada en Filosofia per la Università degli Studi de Parma (Itàlia). Ha traduït assajos de filosofia i novel-les d'autors catalans, espanyols i sud-americans (Albert Sánchez-Piñol, Felipe Benítez Reyes, Marcos Giralt Torrent, Rosario Ferré, Rafael Chaparro Madiedo, entre d'altres). En 2006 va guanyar el VI Premi de Traducció Literària de l'Institut Cervantes d'Itàlia per la traducció de la novel-la de Felipe Benítez Reyes, Lo Sposo del mondo (Fazi, 2004).
} 
Frediani publicà una columna a La Repubblica amb una foto de la coberta del llibre, la síntesi argumental i un breu currículum de Riera esmentant les dues obres anteriorment girades a l'italià, on s'hi destaca: "una scritura densa d'introspezione psicològica e senza cedimenti", que confirma que "literatura e vita non sono poi così distanti” (Frediani, 2007: 38). Igualment, Antonio Calabrò, a una altra ressenya titulada "Alla ricerca dell'amore perduto", collloca Riera al costat d'autors tan famosos com a Orhan Pamuk o l'irlandès John Banville, pel fet de resseguir amb l'escriptura l'entrellat dels sentiments (Calabrò, 2007: 150). Al seu torn, Francesco Luti destaca que Riera "ci regala così un'altra opera rilevante da aggiungere alle precedenti che già la segnalano come una scrittrice particularmente interesante nel panorama odierno della letteratura." (Luti, 2007: 371-372). Igualment apunto a peu de plana les ressenyes crítiques que es fan ressò d'aquesta novel.la. ${ }^{9}$

Tot i que ara per ara no tenim més traduccions de Riera a l'italià, el fet que el públic d'Itàlia pugui fruir d'aquestes tres obres magistrals apunta cap a la seducció que l'escriptura rieriana ha exercit sobre un bon grapat de lectors exigents. Si més no, l'alta qualificació dels traductors i dels crítics que se'n han ocupat semblen provar-ho.

\section{Carme Riera, una autora seduïda per Itàlia: escenaris, personatges i referències}

Les ciutats italianes que formen part dels escenaris de les novel.les de Riera representen la possibilitat de contactar directament amb la bellesa de la cultura clàssica d'Occident, a través de l'art i la literatura, fins i tot visible en l'harmonia urbanística i l'arquitectura dels vells edificis. Potser, precisament per això, aquest paisatge urbà propicia la possibilitat de retrobar o de començar una vita nuova, lluny dels lligams quotidians del país d'origen, de les pressions socials o de la persecució política, ideològica o religiosa d'una societat menys oberta i menys tolerant.

En aquest sentit, les ciutats italianes representen, en primer lloc, la llibertat que hom pot trobar més enllà del "darrer blau". Com és el cas de Livorno. Una frase popular mallorquina diu: "A Liorna qui hi va, no torna”, és a dir, qui aconsegueix arribar a aquelles terres s'hi queda. Com s'hi haurien quedat els fugitius mallorquins de Dins el darrer blau si haguessin aconseguit escapar de l'illa. Liorna suposava pels jueus conversos la llibertat religiosa (no cal recordar que la novel.la se situa a finals del segle XVII) i la possibilitat de prosperar socialment sense les traves d'una rígida estructura estamental tancada en si mateixa:

\footnotetext{
${ }^{9}$ Vegeu Antonella Ottolina (2007: 124), ADN Kronos (s/a) (2007), Bruno Arpaia (2007: 33), La Cronaca (2007: 31), Elena Dallorso (2007: 111), Angela Bianchini (2007: 7), Marilia Piccone (2007) i Psychologies (s/a) (2007: 38).
} 
A Liorna, li havia dit Pere Onofre, tothom és ric. Jo mateix, que no tenc una gran fortuna, puc mantenir carruatge. Aquí [es refereix a Ciutat] cap jueu no en pot tenir. Cap luxe no els és permès. Tampoc la seda. A Liorna, Aguiló va en carruatge fins a les portes de la sinagoga. Ningú s'amaga de ningú. Això és viure a pler -li ha repetit-. Hauríem de cercar sa manera que tu i el Cònsol... (Riera, 1994: 99)

Són diversos els personatges importants de la novel.la que tenen una estreta relació amb Livorno, començant pel mercader Pere Onofre Aguiló, les paraules del qual acabem de reproduir, i que, si bé és un personatge inventat per Riera, es una figura que es correspon històricament amb la dels comerciants mallorquins que feien negocis a la Mediterrània (Ensenyat, 2008: 15-28) i (Montaner, 2010: 95-186). En la trama narrativa, Aguiló és el representant d'altres mercaders i senyors de l'illa dedicats a negocis d'exportació d'oli i importació de peces de lli. És, a més a més, l'encarregat del síndics mallorquins per establir un pacte entre el port de Ciutat i el de Liorna que afavoreixi el comerç entre ambdues ciutats, “ja que [Aguiló] era persona respectada en aquella República, on tenia casa i on havia deixat dona i infants" (74). Aquest mercader és qui organitza la fuita d'“els seus germans" [de casta], dels criptojueus, i qui mira de treure-los sigui com sigui de Mallorca. Per això vol involucrar el seu amic Salomó Abrahim i sobretot la rica viuda del mercader Sampol, Blanca Maria Pires, un dels personatges més fascinants, qui havia viscut anys enrere a Ciutat i a hores d'ara està establerta a Liorna. D'ella espera que "s'avindria a col-laborar amb els doblers que fossin necessaris" (149), com efectivament succeeix. Blanca Maria Pires fa tot el que pot des de la ciutat italiana per ajudar els que volen fugir, fins i tot els envia - ja a la desesperada - el mariner João Peres, amb qui comença i acaba la novel.la i qui també viu a Liorna al seu servei. Tanmateix, tot és inútil, els fugitius han estat capturats i conduïts a la presó de la Casa Negra, processats per la Inquisició: trenta-set són condemnats al braser. Quan João Peres arriba a Porto Pi en la sagetia, no té temps més que de contemplar horroritzat la cremadissa ferotge, abans de tornar a embarcar per "anar-se'n tot d'una, lluny, ben lluny, [...] de presa, enfora, molt enfora, dins el darrer blau" (427), amb tota seguretat cap a Liorna.

A la última novel-la de Riera, Natura quasi morta, tot i que l'acció transcorre a Catalunya, sobretot a la UAB i a Barcelona ciutat, i que es tracta d'una novel.la negra, hi trobem diversos detalls que ens permeten afirmar que, dins la trama narrativa, Itàlia representa de nou una mena de model de societat més progressista i tolerant que no pas la nostra. No és casual que l'autora trii dues estudiants Erasmus italianes: Laura Cremona i Domenica Arrigo com a prototipus de noies universitàries completament alliberades sexualment i que viuen al marge de qualsevol convencionalisme tradicional. Menys casual encara ho és el fet que una d'elles, Laura Cremona, tingui "dues mares", i no un pare i una mare com era d'esperar. Quan la professora Casasaies va a l'aeroport on 
arriba el vol d'Alitalia que porta els pares de la noia desapareguda, es troba amb una situació inesperada:

—La Laura no té pare. Nosaltres... [...]

La senyora Cremona ho volgué notificar de seguida per evitar malentesos, i perquè no li fessin preguntes sobre el pare biològic, els digué que Laura era fruit d'una inseminació artificial. Elles, casades a Amsterdam, on Margaret, malgrat ser alemanya, havia viscut la major part de la seva vida, es consideraven alhora i indistintament pare i mare de Laura. (48)

Una declaració que preocupa la professora, "per si a la universitat algú, sense voler, ficava la pota” (48). Val a dir entre parèntesi que la redacció de la novel.la coincideix amb l'època que les Corts Espanyoles van aprovar la polèmica llei de matrimoni homosexual presentada pel govern del president Zapatero.

A l'altre extrem, els pares de Domenica Arrigo són un matrimoni tradicional arrelats a Nàpols, catòlics practicants, a qui "els consols de la fe els podien ajudar a l'hora d'haver-se d'empasar el terrible tràngol" (168). Finalment, el cònsol italià Dante Braccalente és l'arquetipus del bon vivant, un home alegre i optimista que gairebé sempre està de bon humor i disposat a fruir dels plaers de la bona taula.

Vet aquí, doncs, amb tres pinzellades, un dibuix de la Itàlia dels nostres dies: les elegants i sofisticades senyores de Milà, una família de la petita burgesia del sud, i un romà, espavilat i simpàtic, capaç de manejar amb diplomàtica habilitat les situacions més difícils i tràgiques.

Pel que fa als referents culturals relacionats amb Itàlia, l'escriptura de Riera n'està farcida i els trobem fins i tot a novel-les situades ben lluny d'aquestes terres. Per posar-ne només un exemple. A Cap al cel obert, la novel.la cubana, hi ha un llarg i claríssim homenatge a Il Gattopardo de Giuseppe Tomasi di Lampedusa a l'escena - $\mathrm{i}$ dic 'escena' perquè també hi està ben present l'homenatge a la pel-lícula de Visconti- de la gran festa a casa dels Fortalesa, descrita al capítol XXI. La descripció dels preparatius, especialment de les taules esplèndidament guarnides i copiosament proveïdes de tot tipus de menjars, ens remet a aquestes dues obres cabdals de la literatura i el cinema del segle XX. Aquesta relació intertextual encara es fa més palesa en confrontar l'original de Lampedusa:

Al disotto dei candelabri, al disotto delle alzate a cinque ripiani che elevavano verso il soffitto lontano le piramidi di "dolci di riposto" mai consumati, si stendeva la monotona opulenza delle tables à thé dei grandi balli: coralline le aragoste lessate vive, cerei e gommosi gli chaudfroids di vitello, di tinta acciaio le spigole immerse nelle soffici salse, i tacchini che il calore dei forni aveva dorato, le beccacce disossate recline 
su tumuli di crostoni ambrati decorati delle loro stesse viscere triturate, i pasticci di fegato grasso rosei sotto la corazza di gelatina, le galantine color d'aurora, dieci altre crudeli colorate delizie: all'estremità della tavola due monumentali zuppiere d'argento contenevano il consommé, ambra bruciata e limpido. I cuochi delle vaste cucine avevano dovuto sudare fin dalla notte precedente per preparare questa cena. (Lampedusa, 1969: 206-207)

Amb la traducció de Francesco Ardolino, tal com va fer Natale Tedesco, a l'esmentada "Trobada d'especialistes...", en referir-se a Verso il cielo aperto, aleshores encara inèdita.

Su due lunghi tavoli con tovaglie di lino con dei fiori blu ricamati, attendevano le pietanze condite: le aragoste bollite, su enormi vassoi, avevano un colore rosaceo che si ripeteva perfettamente nei vestiti di alcune ragazze, le spigole senza spine conservavano le curve grigiastre ed erano state ricomposte, decapitate e avvolte in teneri nasturzi. Gli chaud-froids di vitello e i polli arrosto, dalla pelle quasi dorata, mantenevano ancora il calore del fomo, poiché erano stati conservati in grandi ghiotte lasciate fino all'ultimo momento a bagnomaria. I prosciutti del1a Westfalia, i pasticci di fegato d'oca, i testicoli tagliati a pezzetti e cucinati alla maiorchina, con finocchio e pepe, e altre crudeli leccornie, come la lingua con capperi e le cervella impanate, erano allineati intorno ai vassoi con insalate varie, delizie all'uovo, gelatine e salse deliziose oltre ai vol-au-vent farciti di besciamella. Poi, per esplicito desiderio di Gabriel, c'era - anche se mezzo nascosto- un gran vassoio con fette di pane, pomodoro e prosciutto: si era abituato a fare così colazione in Catalogna e gli dava soddisfazione vedere la pietanza ora nel buffet tra le altre squisitezze internazionali. Alle estremità dei tavoli, immense zuppiere d'argento lavorate da eccelsi orefici inglesi servivano per abbellire e allo stesso tempo per accogliere la specialità del cuoco, il delicatissimo consommé di tartaruga. (Riera, Riera, 2002: 226-227)

És curiós però, llegint l'escena del ball de Cap al cel obert, no puc evitar que en la meva imaginació, el senyor de Fortalesa, cubà d'ascendència mallorquina, es transfiguri en una mena de príncep de Salina reencarnat en Burt Lancaster.

Com ja hem avançat abans, l'obra més italiana de Riera és Una primavera per a Domenico Guarini (1981), ${ }^{10}$ la seva primera novel.la. Dins les seves pàgines, podem recórrer escenaris, conèixer personatges i descobrir referències intertextuals i culturals de tota mena.

\footnotetext{
${ }^{10}$ Riera va rebre el premi Prudenci Bertrana de 1980 per aquesta obra.
} 
El punt de partida és el viatge que una periodista mallorquina, arrelada a Barcelona, Isabel Clara Alabern emprèn cap a Florència, enviada pel diari català La Nació, per seguir de prop el judici contra Domenico Guarini, acusat d'agredir la figura de Flora del quadre L'Al-legoria de la Primavera de Botticelli a la Galeria dels Uffizi. La seva missió és enviar les cròniques del judici al diari on treballa, però l'interès de la periodista va més allà: vol esbrinar els motius psicològics que van portar Guarini a atemptar contra el quadre, i a la vegada trobar la clau per resoldre un dilema personal. Davant del quadre, ja restaurat, Isabel Clara s'adona que el cas Guarini i el seu tenen molts punts en comú, i que potser la clau d'ambdós enigmes és dins el missatge hermètic que guarda La Primavera, un missatge, però, que només serà revelat a aquells que tenen la capacitat per a transformar-se.

Florència és doncs l'escenari principal de la novel.la i, alhora, el lloc ideal per a les reflexions que porten la protagonista cap al desenvolupament de la seva identitat, tant per l'estil de vida de la gent que hi habita com per la quantitat d'art per metre quadrat que hi pot respirar.

Segons la meva opinió, el fet que inspirà Riera per ordir el cas Guarini no és l'atemptat contra el quadre de Botticelli, que sortosament mai no va succeir, sinó l'atac brutal que sofrí la Pietà de Miquel Àngel a la Basílica de Sant Pere el 21 de maig de 1972 (diumenge de la Pentecosta), per part d'un geòleg australià anomenat Laszlo Toth, qui amb un martell ferí repetidament el rostre i el braç de la Mare de Déu. L'autor d'aquesta salvatjada, que estremí el món, va ser declarat boig i tancat a un manicomi italià durant un any. Hores d'ara encara impressiona veure el vídeo, penjat a YouTube, que aboca a reflexionar sobre les enigmàtiques raons que porten un ésser humà a fer el mal de manera tant gratuïta.

El fet que impressionà Riera la porta a imaginar la destrucció de $L a$ Primavera de Botticelli, un dels quadres preferits per l'autora. ${ }^{11}$ Sobre aquest tràgic incident, es desenvolupen dues línies argumentals paral-leles, que conflueixen d'alguna manera en el desenllaç final: la història de l'enamorament foll de Domenico Guarini vers Laura Martuari i el desenvolupament del dilema interior en el qual està atrapada la protagonista Isabel Clara.

La fascinació de l'escriptora per la ciutat de l'Arno es fa palesa a l'evocació dels espais més emblemàtics: el baptisteri de Sant Joan Baptista a Piazza del Duomo, les portes del qual esculpides per Ghiberti, que "Dant, exiliat, recorda anomenant 'il mio bel San Giovanni" (64), la Galeria Uffizi, el Ponte Vecchio... Igualment, a la menció reiterada dels indrets freqüentats pels personatges: la via Pellicceria, Piazza della Republica, Piazza di San Firenze, Lungarno Vespucci, vora l'Arno, l'estació de Santa Maria Novella, el barri de San Niccolo, la presó

\footnotetext{
${ }^{11}$ Durant anys Riera ha portat a classe un pòster de La Primavera per il.lustrar l'Humanisme i la literatura del Renaixement.
} 
d'homes de La Murate, ${ }^{12}$ la redacció del Paese Sera, els jardins de Boboli, etc., etc. que es despleguen davant els ulls dels lectors com un immens plànol de la ciutat.

Tot i que tampoc Florència no defuig la mirada mordaç de Riera:

Florència fóra una ciutat meravellosa si hom pogués prescindir de la gent, sobretot dels turistes, veritables ramats, els sorolls, els aparells de TV posats a tota pastilla, els "travoltini" que es parlen a crits entre el renou infernal de les seves "Duccattis" $i$, en certs moments, dels mateixos italians: el seu gust porroner pels "ligues" resulta francament desagradable. Tret d'això, Florència és una ciutat que no em meravella, m'encisa. (61)

D'altres vegades, en canvi, la descripció sembla treta de l'escenari tòpic d'una pel-lícula neorealista:

Aquest barri és allunyat del centre, aquí no arriben els turistes. Fa calor. $\mathrm{Hi}$ ha sorolls de televisió defenestrant-se. Bosses d'escombraries apilades, bosses rebentades pels gossos... Fems arreu. Era per aquí, tombant a la dreta... Una renglera de cases. Roba estesa, quieta, ni un alè d'oratge... Ets a la vora. El cor et va més de pressa... Quina bajanada! T’hi atures al davant. La porta es tancada. La veïna del primer pis pren la fresca en combinació, al balcó, vora el seu marit que duu calçotets i samarreta. Com aleshores... Els reconeixes, no han canviat en cinc anys. No, pots estar-ne segura, no et veuran: badoquen fixos, embiaixats cap a l'altar de la televisió que és dins, al bell mig del menjador. $[\ldots]$

Quatre o cinc-cents metres, tot el que falta per tornar a casa... Començaven a construir el bloc aquell estiu. Poc t'ho imaginaves que Albert es quedés amb un pis...! San Niccolo és un barri agradable... (67).

I fins i tot es converteix en una ciutat qualsevol "bruta, plena de papers $\mathrm{i}$ deixalles. D’una claveguera surt una rata que es creua en el teu camí” (77).

Per altra banda, la immersió dins l'ambient italià comporta també farcir el text d'al-lusions a les circumstàncies polítiques i socials de la Itàlia dels anys 70, els anomenats "anys de plom" de la lluita de les Brigate Rosse contra el sistema, que d'alguna manera culminà amb el segrest i assassinat d'Aldo Moro. Carabinieri, terroristes, advocats, periodistes, estudiants, cambrers, porteres... formen part de la munió de personatges secundaris que pul.lulen per les pàgines de la novel.la tot dibuixant el mosaic de la societat italiana de llavors.

\footnotetext{
${ }^{12}$ Fou presó fins el 1985; des del 2004 és un "Complesso Culturale”.
} 
En aquesta mateixa línia topem també amb l'evocació d'altres ciutats italianes com és el cas de Nàpols, de la qual es descriu el bombardeig per part de l'aviació aliada "una nit de juny del 1942" (55); Milà (59), a la qual s'al.ludeix a propòsit de l'important moviment feminista desenvolupat a partir de la Llibreria de les Dones, partidàries radicals del feminisme de la diferència; i al Teatro delle Donne, ${ }^{13}$ que va sorgir igualment del moviment feministe dels anys 70 . Bari, on es localitzada Laura Martuari (63); Brescia (65); Roma (69), on aleshores s'havia produït la detenció d'un presumpte membre de Prima Linea, organització armada alternativa a les Brigate Rosse (62-63), en relació amb assassinat de Moro (Paese Sera), (1948-1994); Pàdua, residència dels pares de Laura fins que es separen (70); Bologna; Siena, etc.

Indubtablement, l'atracció que Riera sent per Itàlia rau també en les similituds que podem establir amb Mallorca. La dolçor de la llum dels paisatges de la Toscana, l'elegància dels vells edificis, l'ombra clara dels carrers estrets del cas antic, els mobles i quadres que pengen de les parets dels casals senyorials de Ciutat... són a la base de les seves afinitats emotives.

Des del meu punt de vista, però, més important encara que en la fascinació pels espais físics, la influència d'Itàlia a l'obra de Riera es fa present en les referencies constants a la literatura i l'art. En concret, el Canzoniere de Petrarca i La Primavera de Botticelli són els fils d'Ariadna que condueixen el lector cap al significat simbòlic de la novel.la.

Ja d'entrada, al començament de la novel.la, quan Isabel Clara recorda la targeta que acompanyava el ram de flors que Albert li havia enviat cinc anys enrere, ens trobem amb una citació literal del Canzoniere: "Beneeixo l'hora, el jorn, el mes”, traducció al català del vers “Benedetto sia’l giorno, e’l mese, el'anno..." del sonet LXI.

Aquesta primera picada d'ull de la narradora ens avança la pauta sobre la qual es desenvolupa el tema de l'enamorament. No és estrany, doncs, que la noia que inspira aquest sentiment a Domenico Guarini s'anomeni Laura, en al.lusió transparent a la misteriosa dama d'Avignon que inspirà Petrarca. ${ }^{14}$ També, el cognom del personatge Martuari, sembla construït sobre Portinari, al seu torn, cognom de la Beatrice de Dante, les penjades del qual seguia Petrarca.

I si el poeta de Rime in vita e in morte de Madonna Laura la veié per primera vegada el 6 d'abril de 1327, Divendres Sant, i mai no podrà oblidar aquest

\footnotetext{
${ }^{13}$ Actualment Centro Nazionale di Drammaturgia delle Donne.

${ }^{14}$ Potser Laure de Noves, casada amb un avantpassat del marquès de Sade, Laure de Sade (13101348); sigui com vulgui, el cert és que Riera la va tenir ben present: "toda la descripción de Laura Martuari es la de Laura de Petrarca. Yo volví a vaciar a Petrarca y el Cancionero, y administré a Laura todos los rasgos que daba Petrarca a Laura. Pero claro, nadie nunca más se fijó en eso; yo me divertí haciéndolo y allí quedó." Carme Riera a Geraldine Nichols (1989: 218219).
} 
moment, i des de llavors es constitueix en l'objecte idealitzat de l'Amor, on conflueixen les virtuts cristianes i la bellesa de l'antiguitat. Guarini veu també la seva Laura per primera vegada un dia d'abril de 1977 (83), Divendres Sant (84), i la segueix fins al Duomo, on la perd. Tampoc Guarini no podrà oblidar mentre visqui, l'instant i l'indret on la veié: "davant la façana escrostonada del número 5 de la Via Vecchietti, on l'asfalt del carrer semblava una mica més obscur" (8182). I "la seva vida —ens dirà més endavant - seguiria per sempre depenent d'un esguard violeta, d'un iris entintat de lilàs, d'uns ulls color de glicines morades." (85). A partir d'això, Guarini viu una passió claustrofòbica, construïda sobre la visió fugaç d'una adolescent ${ }^{15}$ que no retrobarà mai més. Atès que la Laura que troba a la universitat un any després, hom podria confondre-la "amb qualsevol starlette de moda o si més no amb una candidata [...] al concurs de bellesa més ravaler" (69). La dona idealitzada de Petrarca és tanmateix negada a mesura que la realitat del segle XX s'imposa a l'ideal de viure del Quattrocento.

Així, la tensió entre acció i contemplació, aillament i vida pública, amor idealitzat i amor sensual, expressada en la polarització de les antítesis que caracteritzen la vida i l'obra de Petrarca, és experimentada per Guarini de manera grotesca. Tanmateix, Guarini, qui no pot canalitzar la seva passió a través la poesia, intenta viure-la a través de la pintura:

Dibuixava febrilment, empastifava colors amb les barretes de cera, untava els pinzells per, després, fitorar-los sobre una tela tensa. Cada taca li resultava un monstre amenaçant, cada línia un rostre burleta que l'insultava... Havia perdut la facultat de fer un traç lleuger que li permetés recobrar la delicadesa que trobà al moment de dibuixar Laura copiant la reproducció de Flora, potser perquè, la veritable Laura, era cruel, mentidera, plena de falsedat... (96)

Des del quadre de Botticelli, Flora li retorna l'esguard violeta que l'obsedeix. I es per això que ataca la seva figura. Destruint-la, però, salva Laura, la seva Laura deplorable i degradada, d'una destrucció encara més letal, tal com es descobreix a l'epíleg de la novel.la.

Al seu torn, Isabel Clara, davant del quadre ja restaurat, tot escoltant la dissertació acadèmica del professor que explica els secrets de L'Al-legoria de la Primavera als seus alumnes, és capaç d'enfrontar-se finalment amb els seus propis secrets, assumint-los i eliminant alhora el seu poder malèfic. També Clara salvarà la seva pròpia vida i la de l'ésser que porta en el seu ventre, destruït el seu passat.

\footnotetext{
15 "Portava mitjons blancs calats, fins a mitja cama, i la faldilla ampla deixava només al descobert una franja de pell. Enretirats del front per un passador, els cabells rossos li voleiaven sobre l'esquena..." (82).
} 
Per a Riera - opino- l'art imita la vida i la vida imita l'art, en una successió que gira interminable, tot i que sempre és l'art — l'amor i la bellesa de l'art- qui ens salva obrint-nos la possibilitat de viure en una altra dimensió, lluny de les misèries quotidianes i de la basarda que nia a l'interior de les persones.

Tots aquests aspectes assenyalen, em penso, d'una manera prou evident la fascinació que il Belpaese - el país amb més obres d'art per quilòmetre quadrat de la terra- exerceix sobre una autora tan sensible com a Carme Riera. No és doncs, gens estrany que la autora es senti seduïda fins el moll dels ossos per Itàlia.

\section{REFERÈNCIES BIBLIOGRÀFIQUES}

ADN Kronos (s/a) (2007), "Alla recerca della vera identita” [La metà dell'anima], Adnkronos/Adnkronos Cultura, 21 de juliol de 2007.

Ardolino, Francesco (2001), 'Apropiarse del estilo', dossier “Carme Riera 25 años después”, Neus Aguado (coord.), Quimera, 199, gener de 2001:25-28.

Arpaia, Bruno (2007) "Il destino a Port Bou" [La metà dell'anima], Il Sole 24 Ore, 22 de juliol de 2007, p. 33.

Bianchini, Angela (2007), "Madri e figlie di Spagna”, [La metà dell'anima], TTL. La Stampa, 11 d'agost de 2007, p. 7.

-(2003) "Da Majorca, l'eroina è salita fra le nuvole", Tuttolibri, La Stampa, 5 d'abril de 2003.

-(s/d) "Riera, Dove finisce il blu", La Stampa.

Bottone, Pasquale (2003), "Verso il cielo aperto", 15/03/2003, 10/05/2013. $<w w w . i l t e m p o d i l e g g e r e . c o m>$

Broch, Àlex (dir.) (2008), Diccionari de la Literatura Catalana, Barcelona, Enciclopèdia Catalana.

Bungaro, Monica (1998), "Il romanzo di Carme Riera. Ebrei spagnoli in fuga verso la terra dove finisce il blu", Quotidiano di Lecce, Brindisi e Taranto, 3 d'octubre de 1998.

Calabrò, Antonio (2007), “Alla ricerca dell'amore perduto", Il Mondo, 28 de setembre 2007, p. 150.

Calimani, Riccardo (1998), "Di ebrei, di Cose ebraiche e del Resto", Shalom, 10 de gener de 1998.

Carlino, Carlo (s/d), "Dove finisce il blu, romanzo di Carme Riera: Nel differente modo di essere uomini”, Gazzetta del Sud.

Carrascòn, Guillermo (1998), "Il bordello di Maiorca", L'Indice dei Libri del Mese, 7 de gener de 1998.

Colombo, Luisella (2003), "Carme Riera e la 'scrittura della complessità", Il Nuovo, 4 de febrer de 2003.

Chiara, Cristini (1998), “Alla volta di Livorno là, dove finisce il blu”, Messaggero Veneto, 3 d'agost de 1998. 
Dallorso, Elena (2007), "Il Piacere di Leggere" [La metà dell'anima], Donna Moderna, 1 d'agost de 2007), p. 111.

De Benedetto, Nancy (1998), "Dove finisce il blu”, Gazzetta del Sud Ex libris, 5 de gener de 1998.

Ensenyat Pujol, Gabriel (2008), "El Regne de Mallorca i la península itàlica: del tràfec mercantil a les relacions culturals", El Regne de Mallorca: cruilla de gents $i$ de cultures (segles XIII-XV), Palma, Institut d'Estudis Baleàrics: 15-28.

Fantasia, Francesco (2003), "Carme Riera: Un destino di nome Cuba", Il Messaggero 18 de febrer de 2003.

Faraci, Loredana i Natale Tedesco (2000), “Premio Vittorini 2000”, Stilos (supl.) La Sicilia.

Ferrero, Diana (2003), "Matrimonio deciso a carte", Il Sole 24 Ore, 23 de març de 2003.

Frediani, Francesca (2007), "Ricordi dalla Spagna”, La Repubblica, 16 de juny de 2007, p. 38.

Gazzola Stacchini, Vanna (1998), "Fuga dalla Spagna del Seicento. L'abiura e l'avvenente ebrea in cerca di libertà", Il Diario della Settimana, 1 de gener de 998.

Izzo, Paolo (2003), "Da Maiorca a Cuba con ironia catalana”, Quaderni Radicali, 11 de febrer de 2003.

La Cronaca: Tracce di lettura (s/a) (2007), "Alla ricerca della vera identitat", [La metà dell'anima], 26 de juliol de 2007.

La Rosa, Luigi (2003), "Carme Riera, parole tra norma ed estasi”, Prometheus, 3 de febrer de 2003.

La Vecchia, Giovanna (2003), "Verso il cielo aperto", Italia Sera, 18 de febrer de 2003.

Lampedusa, G. Tomasi di (1969), Il Gattopardo, Milano, Feltrinelli.

Luti, Francesco (2007), “Carme Riera, la metà dell'anima”, Nuova Antologia, 1 de desembre de 2007, pp. 371-372.

Marengo, Luca (2003), "Hasta siempre, Carme Riera" [entrevista], TV Radio Corriere, 25 de febrer de 2003.

Masu, Alessandra (2003), "Verso il cielo aperto", Grazia, 25 de març de 2003.

Montaner, P. de (2010), "Viejos y nuevos datos sobre los Tarongí y los Vallseca, judeoconversos mallorquines ennoblecidos en Sicilia”, Memòries de la Reial Acadèmia Mallorquina D’Estudis Genealògics, Heràldics i Històrics, Xx: 95186.

Nichols, Geraldine C. (1989), Escribir, espacio propio: Laforet, Matute, Moix, Tusquests, Riera y Roig por sí mismas, Minneapolis \& Minnesota, Institute for the Study of Ideologies and Literature. 
Ottolina, Antonella (2007), "I Libri della settimana" [La metà dell'anima], A Anna, 26 de juliol de 2007, p. 124.

Parisi, Antonella (2003), "Storia d'amore nella Storia", Gazzeta di Parma, 22 de juny de 2003.

Piccone, Marilia (2007), "I segreti del pasato" [La metà dell'anima], Stradanove.net, 23 d'agost de 2007.

Pigmei, Valentina (2003), "Esplorare la Cuba ottocentesca con Carme Riera", La Stampa, 30 de gener de 2003.

Psychologies (2007), “Avvincente" [La metà dell'anima], 1 d'octubre de 2007, p. 38.

Riera, Carme (1981), Una primavera per a Domenico Guarini, Barcelona, Edicions 62.

-(1989) "Grandeza y miseria de la epístola”, El oficio de narrar, Marina Mayoral (ed.). Madrid, Cátedra: 147-158.

-(1994) Dins el darrer blau, Barcelona, Destino.

-(1997) Dove finiste il blu, Francesco Ardolino (trad.), Roma, Fazi Editore.

-(2000) Cap al cel obert, Barcelona, Destino.

-(2002) Verso il cielo aperto, Francesco Ardolino (trad.), Roma, Fazi Editore.

-(2004) La meitat de l'ànima, Barcelona, Proa.

-(2007) La metà dell'anima, Ursula Bedogni (trad.), Roma, Fazi Editore.

-(2011) Natura quasi morta, Barcelona, Edicions 62.

Schisa, Brunella (2003), "La Cuba di fine ottocento tra storia, fato e feuilleton", Il Venerdi, La Repubblica, 21 de febrer de 2003.

Taglietti, Cristina (2002), "Feuilleton alla Cubana", Io Donna, 30 de novembre de 2002.

Trani, Riccardo (2003), "Carme Riera, la nuova Regina del romanzo storico", Avanti, 16 de febrer de 2003.

Zandel, Diego (2003), "Destini verso il cielo aperto", La Gazzetta del Mezzogiorno, 30 de març de 2003. 